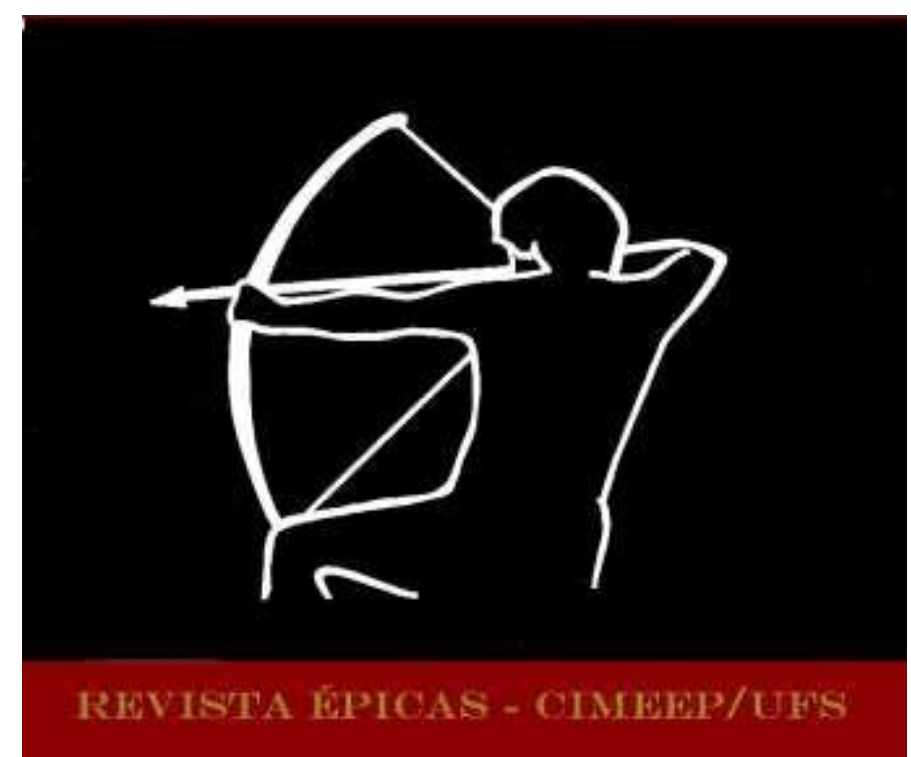

OKAMOTO, Monica Setuyo; KRASOTA, Alisson Gebrim. O mito kappa como relato etnográfico. In: Revista Épicas. Ano 5, N. 10, Dez 21, p. $82-$ 96. ISSN 2527-080-X.

DOI: http://dx.doi.org/10.47044/2527-080X.2021v10.8296

\title{
O MITO KAPPA COMO RELATO ETNOGRÁFICO
} THE KAPPA MYTH AS ETHNOGRAPHIC REPORT

\author{
Monica Setuyo Okamoto ${ }^{1}$ \\ Universidade Federal do Paraná - UFPR \\ Alisson Gebrim Krasota² \\ Universidade Federal do Paraná - UFPR
}

RESUMO: O conto “Kappa” (1927), de autoria do escritor japonês Ryûnosuke Akutagawa (1892-1927), gira em torno do relato de um homem conhecido apenas como paciente número 23, interno do Manicômio S., que conta que viveu uma temporada na terra dos kappas (seres meio humanoides e meio anfíbios, da mitologia japonesa) e descreve o modo de vida deles em comparação com o da sociedade japonesa. O movimento antropológico de tornar familiar o estranho mundo dos kappas e, em contrapartida, tornar exótico o mundo humano, perpassa todo o conto. O objetivo deste trabalho, portanto, é explorar a ideia do mito kappa como relato etnográfico, analisando, por um viés antropológico, a viagem imaginária (ou não?) do protagonista, o paciente psiquiátrico número 23, ao mundo desses seres mitológicos. Palavras-chave: Kappa; Relato Etnográfico; Mito; Ryûnosuke Akutagawa.

ABSTRACT: The short story “Kappa” (1927), by the Japanese writer Ryûnosuke Akutagawa (1892-1927), revolves around the story of a man known only as patient number 23, an inmate at the $S$. insane asylum, who tells that he lived a season in the land of the kappas (half humanoid and half amphibians, from Japanese mythology) and describes their way of life in comparison with that of Japanese society. The anthropological movement of making the strange world of the kappas familiar and, in turn, making the human world exotic, runs through the entire tale. The aim of this work, therefore, is to explore the idea of the kappa myth as an ethnographic report, analyzing, from an anthropological perspective, the imaginary journey (or not?) of the protagonist, psychiatric patient number 23, into the world of these mythological beings.

Keywords: Kappa; Ethnographic Report; Myth; Ryûnosuke Akutagawa

\footnotetext{
${ }^{1}$ Doutora em Letras pela Universidade de São Paulo e Professora Associada do Departamento de Letras Estrangeiras Modernas, da Universidade Federal do Paraná. E-mail: setuyo2@gmail.com. https://orcid.org/0000-0003-3014-6783.

12 Mestre em Antropologia pela Universidade Federal do Paraná (UFPR, 2016) e graduando em Letras Japonês pela mesma instituição. E-mail: algebrim@gmail.com.
} 


\section{Introdução}

Não se trata de chegar ao consenso, mas ao conceito. Eduardo Viveiros de Castro

Queremos dizer uma coisa simples sobre a psicanálise: ela encontrou frequentemente, e desde o começo, a questão dos devires-animais do homem [...] O que se pode dizer, no mínimo, é que os psicanalistas não entenderam [...] No animal, veem um representante das pulsões ou uma representação dos pais. Não veem a realidade de um devir-animal, como ele é o afecto em si mesmo, a pulsão em pessoa, e não representa nada.

Gilles Deleuze e Félix Guattari

Este artigo tem como pretensão analisar, sob um viés antropológico, o conto intitulado "Kappa" ${ }^{3}$, de autoria do escritor japonês Ryunosuke Akutagawa. Publicado em 1927, a obra gira em torno do relato do paciente número 23, interno do manicômio S., que relata ter passado uma temporada no subterrâneo mundo dos kappas, aprendendo sobre seus modos de vida. A ocasião ocorreu quando o protagonista estava subindo o monte Hodaka e, de repente, deparou-se com um kappa o observando. Ao invés de fugir, passou a persegui-lo, mas caiu por um buraco na terra dos kappas, onde passou a conviver com eles. Na mitologia japonesa, kappa é um ser meio hominídeo, meio anfíbio, que vive junto às águas e costuma afogar humanos distraídos.

Evidenciaremos o caráter antropológico do relato do paciente número 23: a descrição que faz da constituição física dos kappas e de seus modos de vida (economia, religião e sexualidade), bem como a comparação com a sociedade humana. A verossimilhança conferida ao mito pelo tom etnográfico do relato é aqui encarada como uma versão atualizada do mito. Portanto, iremos nos pautar pela análise estrutural do autor das "mitológicas", o antropólogo Lévi-Strauss (2008), porém, para analisarmos as oposições que aparecem no mito, empregaremos outra noção de dialética, mais recente e que nos pareceu de maior rendimento analítico, isto é, a dialética da obviação proposta pelo antropólogo Roy Wagner (2011).

Demonstraremos que tanto a análise estrutural, quanto a dialética da obviação não são métodos exógenos que serão aplicados mecanicamente neste artigo. Antes e pelo contrário, sustentaremos que os métodos de análise vão ao encontro do gênero e do estilo do conto, e este será o norte para as proposições que serão aqui apresentadas.

A primeira proposição é a de que, assim como kappa é um mito, o gênero profundo do conto "Kappa" também seria um mito, portanto, a análise estrutural, em seus movimentos de diacronia e sincronia, seria adequada. A segunda é a de que o conto "Kappa" tem um estilo dialético como eixo de desenvolvimento e que o método da dialética da obviação irá evidenciar tanto o caráter antropológico, quanto o caráter dialético

\footnotetext{
${ }^{3}$ Doravante, aparecerão no texto os seguintes termos assim grafados: "Kappa" e kappa. O primeiro, maiúsculo, em itálico e entre aspas, será utilizado para se referir ao conto do escritor Ryunosuke Akutagawa, cujo título é Kappa. O segundo termo, grafado em minúsculo, também em itálico, mas sem as aspas, será utilizado para designar o personagem kappa, da mitologia japonesa.
} 
do conto. A terceira e última proposição é a de que o relato do paciente 23 não deve ser reduzido à análise psicanalítica de um indivíduo acometido de esquizofrenia, mas deve ser explorado conforme a esquizoanálise de Deleuze e Guattari (2012) e a teoria do perspectivismo/multinaturalismo de Eduardo Viveiros de Castro (2002; 2015), isto é, não se trata do paciente 23 enquanto indivíduo, mas da posição anômala dele, entendida não no sentido psicanalítico de anormal, mas no sentido de tangente periférica que faz vacilar o eu e que o torna capaz de alianças em devir, de devir-animal, de xamanismo. Por fim, ao propor o paciente 23 como devir-kappa, este próprio artigo seria uma versão do mito. Assim, a tônica que este trabalho busca responder é: Quais seriam as implicações teórico-epistemológicas, caso o relato do interno número 23 fosse levado a sério?

O objetivo deste artigo é duplo e complementar: demonstrar o caráter mítico do conto "Kappa" pela aplicação dos métodos antropológicos empregados pela antropologia na análise dos mitos e apresentar uma versão antropo-filosófica dele enquanto tal, uma Mitofísica ${ }^{4}$. A importância dessa discussão está em apontar para a dialética antropológica presente em Akutagawa, muitas vezes subsumida sob leituras que buscaram ressaltar a crítica social ou o tom fabuloso de uma história infantil.

Salientamos que a comparação da relação do paciente n.23 com kappas ser análoga à relação xamânica entre os ameríndios, não deve ser compreendida etnocentricamente, como, infelizmente, já ocorreu na história da antropologia com a compreensão que aproximava a "mentalidade indígena" com a mentalidade infantil, ou, pior, com enfermidades mentais. Diversamente, a comparação proposta serve para questionarmos nossos próprios pressupostos culturais e deflagar o rendimento analítico que coloca nossa metafísica em perspectiva, ou, como diz Eduardo Viveiros de Castro: "só vale a pena comparar o incomensurável - comparar o comensurável é tarefa para contabilistas" (2015, p.91). É nesse sentido que lançamos a questão: "por que encarar a relação mítica com os kappas como adoecimento (conforme a visão psicanalítica) e não como uma espécie de xamanismo? Ainda, segundo Viveiros de Castro, se me permitem uma longa citação:

O xamanismo é um modo de agir que implica um modo de conhecer, ou antes, um certo ideal de conhecimento. Tal ideia está, sob certos aspectos, nas antípodas da epistemologia objetivista favorecida pela modernidade ocidental. Nesta última, a categoria do objeto fornece o telos: conhecer é "objetivar"; é poder distinguir no objeto o que lhe é intrínseco do que pertence ao sujeito cognoscente, e que, como tal, foi indevida e/ou inevitavelmente projetado no objeto. Conhecer, assim, é dessubjetivar, explicitar a parte do sujeito presente no objeto, de modo a reduzi-la a um mínimo ideal (ou ampliá-la demonstrativamente em vista da obtenção de efeitos críticos espetaculares). Os sujeitos, tanto quanto os objetos, são concebidos como resultantes de processos de objetivação: o sujeito se constitui ou reconhece a si mesmo nos objetos que produz, e se conhece objetivamente quando consegue se ver "de fora", como um "isso". Nosso jogo epistemológico se chama objetivação; o que não foi objetivado permanece irreal e abstrato. A forma do Outro é a coisa.

\footnotetext{
${ }^{4}$ A mitofísica é a compreensão de que nossa metafísica é uma variação possível entre diversas versões míticas. Segundo Eduardo Viveiros de Castro: "All metaphysics is mythophysics; subject, therefore, to the general structural regime of "truth-as-variation," truth in variation, that myths are. The notion of phusis itself is a mythophysical notion, a certain mode of imagining reality, of giving reality an image-one whose philological ethnohistory is full of sound and fury.14 Ameridian perspectivism is a metaphysics insofar as Western philosophy as a whole is a structural variant within mythopoeic imagination as the faculty of variation" (2016, p.261)
} 
O xamanismo ameríndio é guiado pelo ideal inverso: conhecer é "personificar", tomar o ponto de vista daquilo que deve ser conhecido. Ou antes, daquele; pois a questão é a de saber "o quem das coisas" (Guimarães Rosa), saber indispensável para responder com inteligência à questão do "por quê". A forma do Outro é a pessoa. Poderíamos dizer que a personificação ou subjetivação xamânicas refletem uma propensão geral a universalizar a "atitude intencional" identificada por certos filósofos modernos da mente (ou filósofos da mente moderna) como um dos dispositivos inferenciais de base [...] longe de buscar reduzir a "intencionalidade ambiente" a zero a fim de atingir a representação absolutamente objetiva do mundo, faz a aposta inversa: o conhecimento verdadeiro visa à revelação de um máximo de intencionalidade, por via de um processo de "abdução de agência" sistemático e deliberado (VIVEIROS DE CASTRO, 2015, p. 50-51).

Por que não nos deixarmos informar pela episteme indígena do conhecimento por subjetivação?

Feitas essas considerações preliminares, pretendemos apresentar um breve contexto histórico e literário do conto de Akutagawa. Em seguida, trabalharemos com a problemática central do artigo: “(...) e se levássemos o relato do paciente a sério?" Na sequência, serão apresentados os métodos de análise, isto é, o estruturalismo e a dialética wagneriana da obviação. Faremos também a aplicação prática da análise estrutural e da obviação; bem como a introdução à teoria deleuziana do devir e da esquizoanálise. E, por fim, trataremos da teoria do perspectivismo/multinaturalismo de Eduardo Viveiros de Castro, concomitante com a interpretação de que o paciente número 23 seria como uma espécie de xamã.

\section{Contexto histórico e literário de Kappa}

O conto "Kappa", de autoria do escritor japonês Ryunosuke Akutagawa (1892-1927), foi publicado em 1927, no mesmo ano de falecimento do autor ${ }^{5}$. Na época, Akutagawa já era um escritor famoso no Japão que mantinha o seu sustento exclusivamente com as publicações no jornal Osaka Mainichi. Seu talento era reconhecido por escritores consagrados como Natsume Sôseki que o convidara para participar de seu Clube das Quintas-Feiras. Jun'ichiro Tanizaki foi outro importante escritor que prestigiou Akutagawa quando, em 1917, compareceu ao lançamento de Rashomon.

é A crítica literária japonesa, ao que parece, sempre manteve altas expectativas com relação aos trabalhos de Akutagawa e, naturalmente, o lançamento de "Kappa" não seria diferente. Para muitos críticos, este conto é uma sátira ao período Taishô (1912-1925), quando o militarismo e o nacionalismo japonês evoluíam de forma agressiva e irreversível, sem perspectivas de tempos mais amenos; para outros, uma "pregação socialista"; e ainda há alguns que o consideram uma "fábula infantil". Atualmente, o conto é classificado como pertencente à série autobiográfica do autor, juntamente com, por exemplo, Rodas Dentadas (1927; 2010), seu último texto.

O conto é composto por dezoito partes: um prólogo, narrado em terceira pessoa, e mais dezessete seções, narradas em primeira pessoa. No prólogo, o narrador revela que o protagonista, chamado de

\footnotetext{
${ }^{5}$ Ryûnosuke Akutagawa cometeu suicídio aos 34 anos de idade. Os biógrafos especulam que fora em razão do estado de saúde debilitado do escritor.
} 
paciente número 23, "já deve ter mais de trinta anos, mas aparenta bem menos, um lunático bastante jovem à primeira vista" (Akutagawa, 2010: 23) ${ }^{6}$, e está internado no Manicômio S.

Na seção um, narrada em primeira pessoa, o protagonista conta que, certa vez quando subia o monte Hodaka, deparou-se com um kappa. Ambos ficaram paralisados trocando olhares. Embora assustado, o protagonista teve a iniciativa de tentar agarrá-lo e, não conseguindo, passou a persegui-lo. Foi quando caiu por um buraco, perdeu os sentidos, e acordou na terra dos kappas, sendo muito bem recebido com o título de "Cidadão sob Amparo Especial", e passou uma temporada convivendo com eles e aprendendo seu modo de vida.

Na primeira semana, ele recebe o tratamento do médico Tchak que, diariamente, vinha lhe verificar a pressão a pedido de Guel, um kappa descrito como gordo e capitalista, presidente de uma fábrica de vidros e outros empreendimentos. Também vinha visitar-Ihe, Bag, o velho kappa pescador a quem perseguiu.

Já recuperado, o protagonista passa a residir na casa vizinha à do médico e, com o título de "Cidadão sob Amparo Especial", é apresentado a outros kappas. Durante a sua estadia, aspectos políticos, econômicos, filosóficos, religiosos, ideológicos e de gênero são abordados. Há uma intertextualidade dialogando com o evolucionismo, capitalismo, socialismo, comunismo, anarquismo, niilismo e com determinismos variados: demográficos, genéticos, de subsistência. Há referências explícitas a autores clássicos japoneses, mas também estrangeiros como Nietzsche, Dostoievski, Darwin entre outros.

Interessante observar como Akutagawa vai construindo os seus personagens kappas, que são marcadamente diversos, dentro de uma "lógica do absurdo" que nos remete ao clássico Alice no País da Maravilhas (1865), de Lewis Caroll. De kappa filósofo Mag, que critica as kappas fêmeas por seus constantes assédios aos kappas machos; ao kappa Guel, dono da fábrica de vidros, que revela que não há desempregados entre os kappas porque o Estado os mata e os transforma em ração, evitando assim o suicídio por estarem desempregados; temos uma gama de kappas com comportamentos e raciocínios inesperados.

\section{Relato "esquizo"}

Exploradores, mercadores e missionários trouxeram diversos relatos do Oriente e do Novo Mundo para a Europa. Era comum nesses relatos alguma fantasia e, principalmente, a ênfase no caráter bárbaro daqueles que lhes eram diferentes. Mas, o ponto aqui não é tanto a produção ou o conteúdo desses relatos, mas sim a sua recepção. As cortes europeias, agentes oficiais e gente ilustrada recebiam os relatos como autênticos ou, quando muito, com apenas alguma reserva. Era incomum que exploradores, mercadores e

\footnotetext{
${ }^{6}$ A edição do conto "Kappa", escrito por Ryunosuke Akutagawa, utilizada neste trabalho foi a 2a edição do livro homônimo publicado pela editora Estação Liberdade no ano de 2010 e que contou com a tradução realizada por Shintaro Hayashi. Doravante, devido à quantidade, todas as citações referentes ao livro irão prescindir da autoria e do ano, citando apenas as páginas, para tornar a leitura mais ágil e limpa.
} 
missionários fossem acusados de mentirosos, loucos ou incapazes de conviverem em sociedade por causa de suas histórias fantásticas. A esse respeito, o antropólogo Roy Wagner comenta:

\begin{abstract}
Um antropólogo experiencia, de um modo ou de outro, seu objeto de estudo; ele o faz através do universo de seus próprios significados, e então se vale dessa experiência carregada de significados para comunicar essa compreensão aos membros de sua própria cultura. Ele só consegue comunicar essa compreensão se o seu relato fizer sentido nos termos de sua cultura. Ainda assim, se suas teorias e descobertas representarem fantasias desenfreadas, como muitas das anedotas de Heródoto ou das histórias de viajantes da Idade Média, dificilmente poderíamos falar de um relacionamento adequado entre culturas (WAGNER, 2010, p. 29).
\end{abstract}

Acrescentamos que as anedotas de Heródoto são anacronicamente anedotas, mas faziam sentido em seu contexto e que o relacionamento adequado entre culturas é, segundo Wagner, uma invenção. Contudo, invenção não significa uma "fantasia desenfreada", mas "é 'controlada' pela imagem da realidade e pela falta de consciência do criador sobre o fato de estar criando" (WAGNER, 2010, p. 40).

De lá para cá, os estudos dos povos ditos "selvagens", "primitivos", "bárbaros", "exóticos" ou "pitorescos" foram sistematizados, ganhando método e nome no século XIX: Antropologia. Essa disciplina, que se encarregou de estudar cientificamente esses povos, consolidou o seu método característico de trabalho de campo com observação participante. Acompanhando a empresa colonial, antropólogos retornaram para a Europa com as mais diversas etnografias de povos de todos os continentes, sendo reconhecidos como tradutores culturais, e prestigiados em sua arte de representação das alteridades. Nenhum antropólogo foi considerado louco por descrever costumes que poderiam ser considerados loucos. Contudo, muitos antropólogos costumavam fazer suas observações científicas munidos de pré-conceitos e olhar colonialista, julgando comportamentos de outros povos e classificando-os ora como "infantis", ora "mentalmente desequilibrados".

Dentro desse contexto, alguns questionamentos nos levaram a refletir: e se os relatos etnográficos feitos por antropólogos ocidentais fossem recebidos com desconfiança pela sociedade? Se fossem julgados, tanto em seu conteúdo, quanto em sua intenção, como mentirosos? E se, diante da insistência em reafirmálos como verídicos, o antropólogo fosse considerado louco? E se o antropólogo também viesse a crer em algumas das crenças dos nativos? E se o antropólogo não mais tivesse a palavra final sobre o sentido nativo, mas agentes de saúde de sua própria sociedade lhe determinassem o sentido do sentido que atribuiu ao sentido nativo? Ainda, e se o antropólogo colocasse em juízo os pressupostos de sua própria cultura e retornasse transformado de sua imersão entre os nativos? Enfim, se até a observação participante fosse colocada em juízo, que dizer do antropólogo em devir? Haveria outro caminho além da loucura, ou seja, considerar o nativo ou o antropólogo como loucos?

Além disso, se o relato etnográfico for uma ficção e a insistência em sua verossimilhança for a prova de sua loucura, em que esta ficção se distingue das demais, tais como: capitalismo, socialismo, comunismo, anarquismo, niilismo? Alguém poderia responder que o tal relato etnográfico não corresponde com a realidade. Mas, e as ideologias? Corresponderiam? Ou não são elas alvos de constantes críticas devido à 
hipocrisia, às contradições entre teoria e prática, ideal e real? Por que certas ficções, no contrassenso da tentativa de realizar utopias, de modo errático, não foram encerradas como loucuras?

Por fim, e se, em vez de pensarmos como seria se os relatos etnográficos fossem encarados como loucura; buscássemos refletir sobre o oposto simétrico, isto é, como seria se considerássemos como um relato etnográfico um relato considerado como loucura? $\mathrm{O}$ que esse relato teria a dizer sobre a nossa concepção de relato e sobre a nossa concepção de mundo?

\section{Método}

Assim como o livro concedeu apenas um curto prólogo ao narrador em terceira pessoa (que qualifica o protagonista segundo a terapêutica ocidental como adoecido), mas dá voz ao paciente na sequência de dezessete seções, também este trabalho valoriza o relato do protagonista, buscando levar a sério o que ele diz. Levar a sério não significa concordar com o paciente, nem acreditar no que ele acredita, nem se converter em paciente. Levar a sério é buscar compreender os seus conceitos, as suas categorias e se deixar afetar por elas; em outras palavras, reavaliar nossos conceitos e categorias numa relação simétrica e reversa. É um processo de colocar nossa epistemologia em perspectiva através do outro, de desnaturalizar nossas categorias de entendimento.

A análise estrutural se mostra adequada por ter um caráter sistêmico de tal forma que a relação entre as partes e o todo são de mesma natureza e capaz de explicar o todo; e a mudança na parte afeta o todo e tem efeitos previsíveis. Na prática analítica do conto, a noção de estrutura implica que o conto pode ser dividido em pequenas partes, completas, mínimas e significativas; e que a relação entre as partes não é apenas diacrônica, conforme a sequência em que aparecem no texto, mas também permitem rearranjos e podem ser organizadas conforme categorias de relação dialética que, pelo paradoxo, ironia, contraste, oposição e contraposição, revelam contradições expressas no texto ${ }^{7}$.

Na medida em que o texto é entendido como mito e o mito apresenta diversas versões, o texto, ao mesmo tempo em que é autônomo, também estabelece relações com outras sincronias de mesma natureza, intertextuais, no sentido amplo do mundo como texto. Portanto, o leitor pode se espantar quando se deparar com partes do conto "Kappa" referenciadas a outros textos. Por exemplo, mais adiante, iremos aproximar eventos narrados no texto de Akutagawa com etnografias posteriores ao autor, mas afins com a temática do evento e com o propósito do autor de apresentar uma versão verossimilhante do mito.

No supracitado "paradoxo, ironia, contraste, oposição e contraposição" que "podem revelar as contradições que se expressam no texto" está o método dialético. De modo geral, o que se entende por dialética, pelo menos num senso comum douto, é a dialética hegeliana, isto é, aquela composta por tese, antítese e síntese.

\footnotetext{
${ }^{7}$ Os termos paradoxo, ironia, contraste, oposição e contraposição não são bem sinônimos e mereceriam uma reflexão a respeito que poderia refinar o método dialético. Contudo, tal empreendimento escapa ao escopo deste trabalho.
} 
HEGEL

\begin{tabular}{|l|l|l}
\hline TESE & ANTÍTESE & SÍNTESE
\end{tabular}

Mas aqui adotamos a dialética da obviação em Wagner, por entender que ela opera melhor com o "outro" de cada termo, isto é, com os pares figura/fundo, natureza/cultura, convenção/invenção. Assim, a cada termo da dialética hegeliana há um correspondente oposto, que não é um único possível, mas múltiplo em sua potência de metáfora.

\begin{tabular}{|c|c|c|}
\hline \multicolumn{3}{|l|}{ ROY WAGNER } \\
\hline TESE (FUNDO) & ANTÍTESE (FIGURA) & SÍNTESE \\
\hline TESE (FIGURA) & ANTÍTESE (FUNDO) & ANTISSÍNTESE \\
\hline
\end{tabular}

Além disso, é preciso ter em mente que a síntese é um resultado que não é final (e isto já aparece na teoria de Hegel!), pois possui uma nova antítese, mantendo assim o espírito dialético do conhecimento. Contudo, na teoria de Wagner, a síntese não é simplesmente o efeito dos termos precedentes, mas é também a causa deles. Portanto, o movimento não ocorre apenas da tese para a antítese, como em Hegel, mas também cada termo (tese, antítese e síntese) tem seu reverso e, além disso, há a reversão da síntese para a tese e a antítese. No célebre resumo de Wagner a respeito de sua teoria: "A causa do efeito é o efeito da causa" (2010, p. 240).

Voltando ao conto, o contraste é uma característica marcante do estilo de Akutagawa. Em "Kappa", a sociedade japonesa é constantemente comparada com a sociedade dos kappas, naquele velho e conhecido movimento antropológico de tornar o exótico, familiar; e o familiar, exótico. Deste modo, ora a ironia é empregada para desnaturalizar o olhar japonês sobre a própria sociedade, como quando os machos kappas são vítimas da perseguição empreendida pelas fêmeas (crítica ao assédio na sociedade japonesa); ora o exagero é empregado para provocar a aparência de um contraste, como quando os kappas desempregados são mortos numa câmara de gás e transformados em ração para alimentar outros kappas.

A indignação do protagonista, quando toma conhecimento desses fatos é, por sua vez, recebida com indignação pelo interlocutor que the deu o seguinte revide: "não fazem vocês também o mesmo quando as filhas dos desempregados japoneses recorrem à prostituição?"(Akutagawa, 2010: p. 44). Essa aproximação entre comestibilidade e relações sexuais não escapou à observação do antropólogo Edmund Leach, "repetidamente os antropólogos têm observado que existe uma tendência universal para fazer uma associação ritual e verbal entre o comer e a relação sexual" (1983, p. 184). 
Outro exemplo é a contradição das personagens entre a prática de suas vidas e as ideologias que sustentam, como podemos atestar no caso do kappa Tok que, apesar de ser adepto do amor livre e desprezar a instituição da família, diz em certa passagem:

Passávamos então por uma pequena janela iluminada. Dentro dela um casal, com certeza marido e mulher, se reunia em torno da mesa de jantar com dois ou três filhotes. Soltando um suspiro, Tok disse de repente: Eu me considero um amante super-homem, mas quando vejo uma cena doméstica como essa também sinto inveja (AKUTAGAWA, 2010, p. 36).

Esse discurso paradoxal também pode ser observado no kappa filósofo Mag que, mesmo criticando o assédio das fêmeas kappas, confessa que, às vezes, gostaria também de ser perseguido: "você não me entende porque não é um kappa. Mas, em alguns momentos, também tenho vontade de ser perseguido por aquelas fêmeas pavorosas!" (2010, p. 39). Outro exemplo nesse sentido é o do kappa sacerdote que apresenta os apóstolos do templo: Strindberg, Nietzsche, Tolstói, Doppo Kunida, Wagner entre outros, mas acaba confessando "Olhe, isto que lhes digo é segredo, não contem a ninguém, por favor. Na verdade, eu também não posso crer em nosso deus." (2010, p.69). Por fim, o próprio protagonista que, apesar de ficar indignado com o destino dos desempregados na terra dos kappas, não hesita em se esforçar por condenar o kappa que the roubou uma caneta, mesmo quando soubera que o ladrão era um desempregado que queria dar um presente para alegrar o seu filho doente. Porém, como a criança falecera, o direito penal dos kappas não podia mais imputar o crime. Em suma, mesmo tomando consciência de que o kappa era desempregado, de que o roubo era para o filho doente, e de que a criança morrera; o protagonista fica inconformado que o pai, enlutado do filho, não fosse preso. A indignação diante da falta de compaixão com o destino dos kappas desempregados não significou que teria compaixão por aquele kappa desempregado, e nem mesmo a trágica motivação do roubo lhe serviu como atenuante para aplacar sua indignação de ter sido roubado, e tampouco sentiu alguma consternação em querer acrescentar o sofrimento da prisão ao sofrimento do luto.

\section{Aplicação do método}

Para comprovarmos a nossa tese de que o protagonista não seria um esquizofrênico, aplicamos a dialética wagneriana ao texto, conforme podemos observar no quadro abaixo:

\begin{tabular}{|l|l|l|l|}
\hline PSICANÁLISE & KAPPA MÍTICO & $\begin{array}{l}\text { MENTE REAL } \\
\text { (ADOECIDA) }\end{array}$ & ESQUIZOFRÊNICO \\
\hline ESQUIZOANÁLISE & KAPPA REAL & CORPO MÍTICO & XAMANISMO \\
& AFECTO-DEVIR & \\
\hline
\end{tabular}


Na primeira linha, teríamos a versão ocidental. Numa vertente psicanalítica, e a partir do seu ponto de vista exógeno ao paciente, a mente que toma a figura imaginária do kappa como real está adoecida numa realidade paralela esquizofrênica. Na segunda linha, teríamos uma contribuição dos filósofos Deleuze e Guattari (2012), para quem a mente não é um teatro de representações, mas uma oficina de produções. Para começar, parte-se do ponto do protagonista, para quem o kappa é real. A relação com o kappa não é imaginária pela mente, mas a partir do corpo, de seus afetos, de suas possibilidades de relação e, tal qual o xamanismo, capaz de transitar e de se conectar com multiplicidades.

Repare nos polos dialéticos entre real e mítico, corpo e mente, tanto numa mesma episteme (linha), quanto numa episteme reversa (coluna), na qual o que é natureza para você pode bem ser a cultura do outro e vice-versa.

Com base nessa dialética foram construídos os mitemas do texto, isto é, as unidades mínimas de composição da história. Nesse sentido, cada mitema encerra em si uma dialética, respeitando e preservando o caráter dialético do texto de Akutagawa. Além disso, o número de mitemas foi selecionado conforme a divisão do próprio autor na construção do conto: prólogo e dezessete seções, totalizando assim dezoito mitemas.

\begin{tabular}{|l|l|l|l|}
\hline sexo/vida & adoecimento/morte & mito & ideologia \\
\hline & 1.o louco lúcido & & \\
\hline & 2. o buraco do monte & & \\
\hline $\begin{array}{l}\text { 3. cidadania } \\
\text { estrangeira }\end{array}$ & & & \\
\hline & & & \\
\hline & 5. parto natimorto & & \\
\hline & & & 6. família $x$ amorossímil livre \\
\hline
\end{tabular}




\begin{tabular}{|c|c|c|c|}
\hline $\begin{array}{l}\text { 7. perseguidor } \\
\text { perseguido }\end{array}$ & & & $\begin{array}{l}\text { 8. censura da música } \times \\
\text { liberdade da pintura }\end{array}$ \\
\hline & $\begin{array}{l}\text { 9. canibalismo e } \\
\text { prostituição }\end{array}$ & & $\begin{array}{l}\text { 10. a paz da independência } \\
\text { é guerra das naçōes. }\end{array}$ \\
\hline & $\begin{array}{l}\text { 11. de ponta cabeça é a } \\
\text { mesma coisa }\end{array}$ & $\begin{array}{l}\text { 12. lógica dos homens: } \\
\text { deus existe, os kappas } \\
\text { não. }\end{array}$ & 13. sensibilidade no roubo. \\
\hline & $\begin{array}{l}\text { 14. frivolidade diante do } \\
\text { suicídio. }\end{array}$ & & 15. o sacerdote incrédulo \\
\hline & & & $\begin{array}{l}\text { 16. o materialismo pós- } \\
\text { morte }\end{array}$ \\
\hline \multicolumn{4}{|l|}{ 17. o jovem velho } \\
\hline & 18. o médico doente & & \\
\hline
\end{tabular}

Reparem que as frases são os mitemas e estes encerram em si mesmos oposições dialéticas; as colunas estão em pares dialéticos: morte $\mathrm{x}$ vida e mito $\mathrm{x}$ ideologia; a ordem numérica dos mitemas é diacrônica, isto é, conforme aparecem na sequência do texto; por fim, as colunas arranjam os mitemas sincronicamente, isto é, conforme afinidades estruturais. O caráter mítico do texto está em sua circularidade, pois tanto o mitema de origem (mitema 1), quanto o mitema de destino (mitema 18), acabam por se encontrar, isto é, parte do manicômio e retorna ao manicômio. Outro aspecto que confirma o caráter mítico do conto é que se invertermos a ordem dos mitemas isso não atrapalhará a compreensão do texto. Nesse sentido, se tivesse sido primeiro apresentada a religião dos kappas para depois apresentar suas relações de gênero ou jurídica ou econômica, a ordem não teria relevância para a compreensão dos eventos.

Na sequência do método estrutural de Lévi-Strauss, apresento agora relatos de etnografias posteriores ao livro, mas que possuem uma relação estrutural com os eventos narrados no conto e, não só $\theta$ ajudam a compreender como vão ao encontro da intenção de trazer verossimilhança ao mito. No conto, o protagonista não era o primeiro humano a viver entre os kappas, pois Bag the contou que houve outros, inclusive um operário de construção de estradas que chegou até a se casar com uma fêmea local e viveu entre eles até morrer. Interessante comentar aqui que Darcy Ribeiro registrou esta prática entre os ameríndios:

A instituição social que possibilitou a formação do povo brasileiro foi o cunhadismo, velho uso indígena de incorporar estranhos à sua comunidade. Consistia em lhes dar uma moça índia como esposa. Assim que ele a assumisse, estabelecia automaticamente, mil laços que o aparentavam com todos os membros do grupo. [...]Como cada europeu posto na costa podia fazer muitíssimos desses casamentos, a instituição funcionava como uma forma vasta e eficaz de recrutamento de mão de obra para os trabalhos pesados de cortas paus-de-tinta, transportar e carregar para os navios, de caçar e amestrar papagaios e soíns. Mais tarde, serviu também para fazer prisioneiros de guerra que podiam ser resgatados a troco de mercadoria, em lugar do destino tradicional, que era ser comido ritualmente num festival de antropofagia. (RIBEIRO, 2015, p.63) 
Assim como para os portugueses, no conto de Akutagawa notamos que a narrativa insinua a vantagem desses casamentos "interétnicos".

Outro aspecto é o aprendizado do idioma kappa pelo protagonista. Seguem as menções ao idioma:

1) “Quax, Bag, quo quel quam?', que, traduzido, seria: ' Ei, Bag, o que foi?” (p.29); 2) “Respondi, é claro, qua (que quer dizer 'sim', na língua deles (P.35); 3) "Mas justo quando ele assim falava, infelizmente uma garrafa vazia caiu em cheio sobre a sua cabeça, e, gritando 'Quak' (apenas uma interjeição), Mag perdeu os sentidos." (p.42); 4) "Guel, mais eufórico que de costume e todo sorridente, falava do ministério formado pelo partido Quorax, então no poder. A palavra quorax em si é apenas uma interjeição sem muito sentido, não há como traduzi-la. Seria algo como 'opa!" (p.45); 5) “[...] Lope. Ele controla o partido Quorax. E é por sua vez, controlado por Cuicui, que preside o jornal Pou Fou (pou fou, na linguagem deles,s é outra interjeição sem sentido. Seria qualquer coisa parecida com 'oh, sim!', se forçarmos uma tradução (P.46)."; 6) “- Não sei o que aconteceu. Ele estava escrevendo e, de repente, deu um tiro na cabeça. Ah, o que vou fazer? Qurrr-r-r-r-r! Qur-r-r-r-r-r-r! (Assim é o choro dos kappas." (p.61); 7) "Vitalismo talvez seja uma tradução incorreta. O termo original é Quemoocha. Cha corresponde ao sufixo 'ismo'. Quemoo vem de quemal, que não quer dizer apenas viver, mas também comer, beber e fazer sexo.)"

(AKUTAGAWA, 2010, p.64).

Ora, desde que os antropólogos pararam de simplesmente analisar relatos de terceiros em seus gabinetes e passaram eles próprios a praticarem o trabalho de campo, convivendo com os nativos para coleta de dados com maior qualidade, estes perceberam a necessidade premente de aprender o-idioma nativo para conseguir compreender o significado e o sentido da cultura.

Por fim, a fala como instrumento de trabalho de parto tanto entre o mundo dos kappas como na etnografia. e o mundo dos humanos que. No conto, durante o trabalho de parto da esposa de Bag, este encosta sua boca no órgão sexual dela e pergunta ao filho se ele queria mesmo nascer, ao que o bebê respondeu negativamente, dizendo temer herdar a insanidade do pai e alegando também que a existência "kappal" não lhe parecia boa.

Lévi-Strauss também relata um parto que ocorre pelo diálogo. Diz o autor que, entre o povo amazônico Cuna, quando a mulher tem problemas no parto, um xamã é chamado para ajudá-la. Ele começa a cantar uma longa canção que narra as forças que estão impedindo o nascimento até o seu desenlace no nascimento do bebê. Segundo Lévi-Strauss:

A cura xamânica e a cura psicanalítica tornar-se-iam rigorosamente semelhantes: tratar-se-ia, em ambos os casos, de induzir uma transformação orgânica, que consiste essencialmente numa reorganização estrutural, levando o paciente a viver intensamente um mito, ora recebido, ora produzido, cuja estrutura seria, no nível do psiquismo inconsciente, análoga àquela cuja formação se quer determinar no nível do corpo (LÉVI-STRAUSS, 2008, p.217)

Destaca-se que sem tocar na mulher, mas apenas com a canção o xamã conduz o parto. 


\section{O paciente número 23 como xamã}

É comum entre os ameríndios a noção de que certos animais são pessoas, porém apenas o xamã teria a cidadania cosmológica para transitar entre os diferentes regimes ontológicos, isto é, seria capaz de conhecer não só os humanos como pessoas, mas também quais animais o são. Segundo Eduardo Viveiros

de Castro: "O xamanismo ameríndio pode ser definido coo a habilidade manifesta por certos indivíduos de cruzar deliberadamente as barreiras corporais entre as espécies e adotar a perspectiva de subjetividades 'estrangeiras', de modo a administrar as relações entre estas e os humanos"' $(2015$, p.49).

Diante desse fato, os antropólogos do século XIX costumavam considerar os indígenas, no tocante à mentalidade, primitivos e infantis. No século XX, buscando combater a noção etnocêntrica de hierarquia entre os povos, os antropólogos tentaram se livrar desse embaraço dizendo que os indígenas se expressavam através de metáforas e representações. Não é que os animais falam, mas é como se falassem. Os indígenas, por outro lado, contestam essa versão. Para o antropólogo britânico Evans-Pritchard:

Não podemos ter uma conversa produtiva ou sequer inteligível com as pessoas sobre algo que elas têm por autoevidente, se damos a impressão de considerar tal crença como ilusão ou delírio. Se fizéssemos isso, logo cessaria qualquer entendimento mútuo e, junto com ele, toda simpatia. (EVANS-PRITCHARD, 2005, p.246).

Diante do exposto, como levar a sério o indígena? Eduardo Viveiros de Castro (2002b) percebeu que não se tratava de salvar a racionalidade indígena, mas sim de questionar os pressupostos ocidentais a respeito da noção de pessoa. O caso é que, para nós, ocidentais, há uma única natureza que é interpretada diferentemente conforme a cultura de cada povo. Unicidade ontológica estável e pluralidade epistemológica variável. Para os indígenas é o oposto, isto é, há uma única cultura para os seres, mas cada ser, conforme o aspecto dos afetos da sua espécie constitui uma relação ontológica múltipla e variável. Unicidade epistemológica da cultura para todos os seres capazes de um ponto de vista e multiplicidade das naturezas ontológicas conforme a relação que se estabelece com cada corpo e afeto do ser.

Por exemplo, um jaguar tem os mesmos hábitos de cultura que um ser humano. O seu pelo é a sua roupa e o sangue que bebe é cerveja. O porco na lama está numa sauna. Cada corpo estabelece uma relação com o mundo. Mas o corpo não é definido por sua anatomia ou fisiologia, mas por seus afetos, sua potência, sua capacidade de ocupar um ponto de vista. A multiplicidade ontológica do mundo é o multinaturalismo e a capacidade de um corpo ter uma relação ontológica com o mundo é o perspectivismo. Nas palavras de Eduardo Viveiros de Castro: 
O perspectivismo não é um relativismo, mas um multinaturalismo. O relativismo cultural, um multinaturalismo, supõe uma diversidade de representações subjetivas e parciais, incidentes sobre uma natureza externa, uma e total, indiferente à representação; os ameríndios propõem o oposto: uma unidade representativa ou fenomenológica puramente pronominal, aplicada indiferentemente sobre uma diversidade real. Uma só 'cultura', múltiplas 'naturezas'; epistemologia constante, ontologia variável - o perspectivismo é um multinaturalismo, pois uma perspectiva não é uma representação.(VIVEIROS DE CASTRO, 2002a, PG.379)

Mas, na crença indígena, o xamã é o único capaz de transitar pelas ontologias, pelos mundos; capaz de ver mortos e espíritos sem morrer ou estar morto; capaz de ver a antropofagia na cadeia alimentar; de ser um "diplomata cosmológico"; de ver a prevalência da pessoa no predador que, por sua vez, é incapaz de reconhecer na presa a noção de pessoa. É no olhar do jaguar sobre o porco que a noção de pessoa é negociada: correr ou enfrentar.

É o xamanismo do paciente número 23 que o impediu de virar presa. Foi o xamanismo que evitou que o seu olhar fosse capturado pelo do kappa e virasse uma presa. Assim diz o texto no primeiro encontro entre o protagonista e o kappa pescador Bag:

Consultei o relógio de pulso enquanto mastigava um naco de pão, e já era uma hora e vinte minutos. No entanto, mais do que o horário, o que me assustou foi ver por um instante, refletida no vidro redondo do mostrador, a imagem de um rosto grotesco. Voltei-me assustado, e - foi essa a primeira vez que me deparei com um kappa. Em cima de uma rocha às minhas costas, lá estava ele, um kappa igualzinho aos que se vê em desenhos, uma das mãos abraçando o tronco de um vidoeiro branco e a outra sobre a vista, a observar-me com curiosidade. Aturdido, fiquei imóvel por alguns momentos. O bicho parecia também assustado, tanto que nem sequer mexia a mão que ainda mantinha sobre a vista. De repente, lancei-me num salto para agarrá-lo em cima da rocha. (AKUTAGAWA, 2010, p.25)

Bag, o pescador, talvez quisesse afogá-lo, como reza a lenda sobre os kappas, mas ficou impressionado desse humano tê-lo flagrado antes do bote e de, no clímax da troca de olhares, ter o humano tomado a primeira atitude que, ao invés de fuga, foi de perseguição. Um pouco mais adiante, o texto ilustra esse potencial sombrio do encontro de kappas com humanos no seguinte relato:

Porém, num tépido fim de tarde, eu estava na sala sentado à mesa bem defronte a Bag quando de repente, por algum motivo, ele emudeceu, arregalou ainda mais seus grandes olhos e ficou me encarando. Achei aquilo muito estranho, é claro, e perguntei: "Quax, Bag, quo quel quam?", que, traduzido, seria: “Ei, Bag, o que foi?” Mas ele não só deixou de me responder, como também se levantou de súbito e mostrou a língua, fazendo menção de pular sobre mim como um sapo. Assustado, levantei-me cuidadosamente da cadeira, pronto para alcançar a porta num salto. Por sorte, chegou nesse mesmo momento o médico Tchak.

- O que está fazendo, Bag, seu malcriado? - disse Tchak, sem retirar seu pince-nez.

Aparentemente intimidado, Bag levou diversas vezes a mão à cabeça e desculpou-se:

- Mil perdões, mas achei engraçado o jeito assustado deste senhor, e por isso me excedi na brincadeira. Senhor, não me leve a mal, sim? (AKUTAGAWA, 2010, p.29) 


\section{Considerações finais}

Mais do que apresentar respostas, este artigo busca instigar nos leitores questionamentos: por que o paciente de número 23 não pode ser considerado normal em sua relação com o mito, assim como aqueles que pretendem tornar utopias em realidade em sua relação com as ideologias? Os mitos são tão coletivos quanto e até mais tradicionais que as ideologias. Afinal, não se trata do paciente número 23 e nem de um kappa qualquer, mas dos afetos do paciente número 23 com a multiplicidade de kappas. O paciente de número 23 não quer imitar os kappas, nem tem para si que é um kappa. Ele apenas tem um devir-kappa. Algo que não é nem kappa, nem humano, mas que tem uma relação direta com o mito. Então, por que uma vivência na relação com o mito agrediria tanto a metafísica ocidental que utopias são normalizadas, mas esse devir-kappa teve que ser confinado?

\section{Referências bibliográficas}

AKUTAGAWA, Ryunosuke. Kappa e o levante imaginário. São Paulo: Estação Liberdade, 2010.

DELEUZE, Gilles; GUATTARI, Félix. Mil platôs: capitalismo e esquizofrenia 2, vol. 4. São Paulo: Editora 34, 2012.

EVANS-PRITCHARD, Edward. Bruxaria, oráculos e magia entre os Azande. Rio de Janeiro: Zahar, 2005.

LEACH, Edmund. Aspectos antropológicos da linguagem: categorias animais e insultos verbais. In: Edmund Ronald Leach: antropologia. São Paulo: Ática, 1983.

LEVI-STRAUSS, Claude. Antropologia estrutural. São Pauo: Cosac Naify, 2008.

RIBEIRO, Darcy. O povo brasileiro. São Paulo: Global, 2015.

VIVEIROS DE CASTRO, Eduardo. A inconstância da alma selvagem - e outros ensaios. São Paulo: Cosac Naify, 2002a.

VIVEIROS DE CASTRO, Eduardo. Metafísicas canibais: elementos para uma antropologia pós-estrutural. São Paulo: Cosac Naify,

2015.

VIVEIROS DE CASTRO, Eduardo. O nativo relativo. Mana 8 (1):113-148, 2002b.

VIVEIROS DE CASTRO, Eduardo. "Metaphysics as Mythophysics". In: CHARBONNIER, Pierre; SALMON, Gildas; SKAFISH, Peter (Org.) Comparative metaphysics: ontology after anthropology. Lanham: Rowman \& Littlefield International, 2016.

p. 249-273.

WAGNER, ROY. A invenção da cultura. São Paulo: Cosac Naify, 2010.

WAGNER, ROY. O apache era o meu reverso. Revista de antropologia. Agosto de 2011, N.2, V.54, p.955978. 